\title{
Forging Advisor
}

Final Report

Prepared under NCMS Project Number 140168 and DOE Agreement Number DE-FC07-94CE41123

Compiled by

National Center for Manufacturing Sciences 3025 Boardwalk

Ann Arbor, Michigan 48108-3266

March 2003 


\section{(c)2003 National Center for Manufacturing Sciences, Inc.}

This report was prepared by the National Center for Manufacturing Sciences (NCMS) as an account of work sponsored by NCMS on behalf of the Department of Energy Office of Industrial Technologies (DOE OIT).The information in this document is proprietary to NCMS. It is protected both under the U.S. Copyright Act and applicable state trade secret laws and may not be reproduced or disseminated without the express written permission of NCMS. Neither NCMS, members of NCMS, nor any person acting on behalf of them:

- makes any warranty or representation, express or implied, with respect to the accuracy, completeness or usefulness of the information contained in this report, or that the use of any information, apparatus, method, or process disclosed in this report will not infringe privately-owned rights, or

- assumes any liability with respect to the use of, or from damages resulting from the use of, any information, apparatus, method, or process disclosed in this report.

This effort is sponsored by the Department of Energy;.

This document contains information developed through the support of the Department of Energy under Agreement No. DE-FC07-94CE41123 and the content of the information does not necessarily reflect the position or policy of the Government; no official endorsement should be inferred. The Government has certain rights in the information and may publish, distribute, translate, duplicate, exhibit and perform such Copyrighted work for Governmental purposes only. 


\section{Table of Contents}

Section

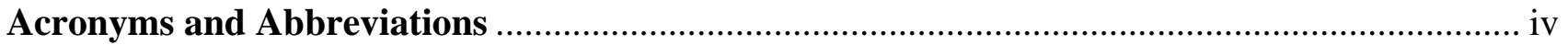

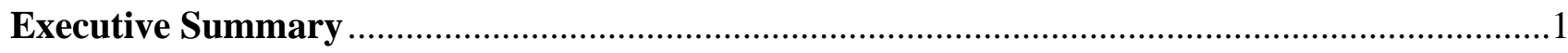

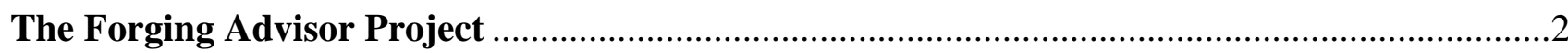

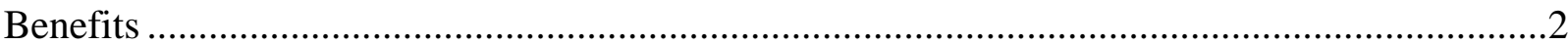

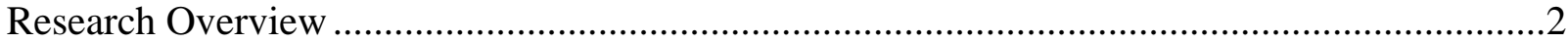

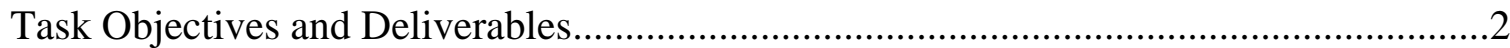

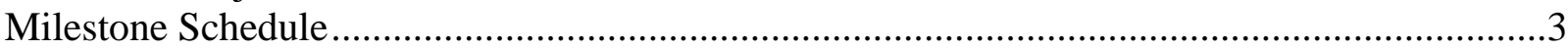

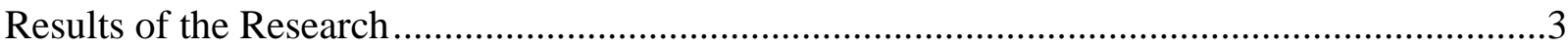

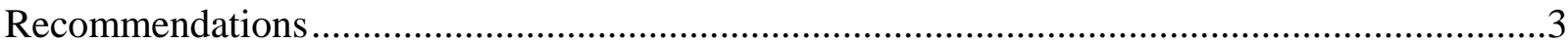

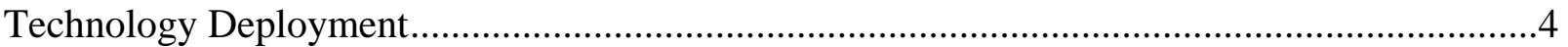

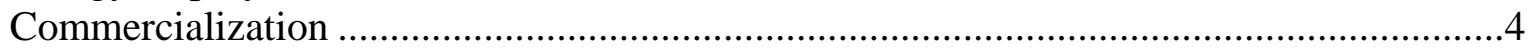

Appendix A - Using Smart Forge Advisors to Support Multiple Points of View in the Design Process ..... 


\section{Acronyms and Abbreviations}

CAD Computer-Aided Design

CBFA Case-Based Forging Advisor

DOE Department of Energy

LENS Laser Engineered Net Shaping

NCMS National Center for Manufacturing Sciences
NNS Near Net Shape

OIT Office of Industrial Technology

U.S. United States 


\section{Executive Summary}

Many mechanical designs demand components produced to a near net shape condition to minimize subsequent process steps. Rough machining from slab or bar stock can quickly and economically produce simple prismatic or cylindrical shapes. More complex shapes can be produced by laser engineered net shaping (LENS®), casting, or forging. But for components that require great strength in mission critical applications, forging may be the best or even the only option.

However, designers of these parts may and often do lack the detailed forging process knowledge necessary to understand the impact of process details such as grain flow or parting line placement on both the forging process and the characteristics of the forged part. Economics and scheduling requirements must also be considered. Sometimes the only viable answer to a difficult problem is to re-design the assembly to reduce loading and enable use of other alternatives.

Recognizing this problem, Sandia National Laboratory computer scientists created a prototype Near Net Shape Process Selection Advisor (NNS Advisor). The prototype demonstrated very good functionality but lacked the detailed process knowledge that can only be derived from collecting and incorporating the lessons learned from real world case studies (see the attached paper in Appendix A).

To support the NNS Advisor, Sandia also created a prototype Case-Based Forging Advisor (CBFA) system. The CBFA provides a simple, easy to use graphical interface for capturing forging cases in a structure database plus a means of describing critical parameters for retrieving relevant case.

The objective of this project was to identify case study sources for aluminum and titanium, arrange data transfer mechanisms, and incorporate knowledge from those case studies into the CBFA and the NNS Advisor.

The mission of this project was to provide to designers a web-based advisor that provides the detailed forging process knowledge now only available from highly experienced forging process engineers.

The advisor system uses an innovative reasoning scheme that is based a (user definable) weighted table. The scheme proved to work well and is much more easily understandable by manufacturing engineers than a more traditional backwards-chaining rule set.

Creation of the software was a straightforward software engineering problem that proceeded smoothly until the project team attempted to obtain real life use cases to populate the basic system. Although forging technology in its most basic form is thousands of years old, modern design techniques are considered highly proprietary. Users proved very reluctant to allow data considered proprietary released publicly, even disguised and un-attributable form. Despite intense effort, the problem proved insurmountable. The data furnished came from the Forging Industry Association and a single user company. 


\section{The Forging Advisor Project}

\section{Benefits}

The primary benefit of this project is capture of highly specialized knowledge for reuse. The system structure is designed to facilitate knowledge retrieval and reuse by personnel skilled in the use of CAD technologies but not necessarily knowledgeable about forging technologies.

Specific benefits enabled are:

- Reduction in the number of forging redesigns required to achieve a design that is manufacturable and meets performance requirements

- Saving energy used to prototype unacceptable designs

- Removing time (and cost) of redesigns from product realization cycles.

\section{Research Overview}

\section{Task Objectives and Deliverables}

\section{Task Objectives}

- Task 1 - Identify the forging companies and end-user industries who are willing to share data and knowledge

- Task 2 - Interview the various engineers and metallurgists to determine the parameters that need to be collected and in what form they need to be collected to represent the forging process knowledge
- Task 3 - Design initial prototype of database and populate with 5-10 cases, which will include analysis of cases to determine key attributes/features

- Task 4 - Initiate development of the inference engine for the case-based reasoning

- Task 5 - Iterate with engineers, metallurgists, and forging houses on representation and content/build retrieval system

- Task 6 - Develop interface with Forging Advisor

- Task 7 - Develop database/knowledge browser

- Task 8 - Finalize database architecture, finalize screens, finalize inference engine prototypes.

\section{Deliverables}

- Case-based forging database architecture and populated database

- Set of "use cases" for the Forging Advisor based on interviews with designers and manufacturers

- Browser for the forging database/knowledge

- Interface to the Forging Advisor

- Case-based reasoning inference engine. 
Page 1 of 1

NCMS Forging Advisor Project

\begin{tabular}{|c|c|c|c|c|c|c|c|c|c|c|c|}
\hline \multirow[b]{2}{*}{ TASK } & \multicolumn{9}{|c|}{2001} & \multicolumn{2}{|c|}{2002} \\
\hline & Apr & May & Jun & Jul & Aug & Sep & Oct & Nov & Dec & Jan & Feb \\
\hline $\begin{array}{l}\text { Task 1. Identify Forging } \\
\text { companies and end-user } \\
\text { industries who are willing to } \\
\text { share data and knowledge }\end{array}$ & $4 / 2$ & & & & & $9 / 18$ & & & & & \\
\hline $\begin{array}{l}\text { Task 2. Interview various } \\
\text { engineers and metallurgists } \\
\text { to determine the parameters } \\
\text { that need to be collected }\end{array}$ & & & & & & & $10 / 16$ & & & & \\
\hline $\begin{array}{l}\text { Task 3. Design initial } \\
\text { prototype of datataase and } \\
\text { poulate with a few (5-10) } \\
\text { cases }\end{array}$ & & & & & & $/ 31$ & & $11 / 15$ & & & \\
\hline $\begin{array}{l}\text { Task 4. Initiate } \\
\text { development of the } \\
\text { inference engine for the } \\
\text { case-based reasoning }\end{array}$ & & & & & & 9/22 & & & & $7 / 18$ & \\
\hline $\begin{array}{l}\text { Task 5. Iterate with } \\
\text { engineers, metallurgists and } \\
\text { forging houses on } \\
\text { representation and content / } \\
\text { Build retrieval system }\end{array}$ & & & & & & & & $11 / 15$ & & & \\
\hline $\begin{array}{l}\text { assk 6. Develop interface } \\
\text { with Forging Advisor }\end{array}$ & & & & & & & & & & 1 & 31 \\
\hline $\begin{array}{l}\text { Task 7. Develop Database / } \\
\text { Knowledge Browser }\end{array}$ & & & & & & & & & & & 31 \\
\hline
\end{tabular}

\section{Milestone Schedule}

\section{Results of the Research}

The research delivered working solutions for the Forging Advisor extensions to Sandia's Near Net Shape Advisor system. The system met all requirements except that the contents of the database of examples for case-based reasoning fell well short of initial expectations due to lack of success in convincing forging users to supply actual cases. The technology is available for licensing from Sandia to commercial vendors.

\section{Recommendations}

These software tools provide the foundation for a forging knowledge capture and advisor system.
They offer an opportunity to reduce the time and cost of designing and acquiring forgings for a variety of applications. Within the time frame of the project, NCMS, Sandia, and the Forging Industry Association were able to find one large user (Sikorsky Aircraft) willing to try the system and provide use cases. The primary barrier was reluctance to expose forging design and process knowledge considered highly proprietary. The most important secondary barrier was reluctance to invest necessary resources to try out unproven technology in a time when, due to the state of the national economy, manufacturers were reducing headcount. NCMS' first recommendation is to once again seek a cooperating user partner once the economy is again healthy. 
The Advisor software is designed so that when a user first accesses the web-based server software, a user client is automatically downloaded to provide better local performance. The download process can be lengthy, especially if access is via dial-up connection. The advisor functions as designed, but the design should be re-examined to find a means of reducing that long wait initial time without compromising performance.

NCMS' second recommendation is that Sandia should, with DoE assistance, find a commercializing partner willing to license and commercialize the technology.

An area not directly associated with the Forging Advisor system but of great interest to users of forgings, especially aluminum forgings, is the prediction of shape distortion due to the relief of internal stresses in forgings as they undergo machining processes. Sandia addressed this area in a report, "Study on the Development of a Machining Advisor for Forged Billets" by Bill Stubblefield, Kim Mitchiner, Tim Mitchell, Bart Chavez and Lothar Bieg.

\section{Technology Deployment}

The NNS Advisor uses a web interface and is designed for access via the Internet. Tools of this sort are becoming more common on industrial portals.

The Case Browser software is designed so that it can be installed over an enterprise database, such as Microsoft's SQL Server. In that configuration, it would be an excellent corporate forging technology knowledge management system. NCMS' third recommendation is that Sandia should, with DOE assistance, find a commercial knowledge management partner willing to license and commercialize the technology.

\section{Commercialization}

NCMS has sought commercialization partners to bring this technology to market.

\section{Licensing}

There was no licensing within the timeframe of the project. 


\title{
Appendix A
}

\section{USING SMART FORGE ADVISORS TO SUPPORT MULTIPLE POINTS OF VIEW OF THE DESIGN PROCESS}

\author{
K. W. Mitchiner*, W. Stufflefield*, J. Herzer*, S. Kleban*, D. Chellman** \\ * Sandia National Laboratories, Albuquerque, NM 87185 \\ **Lockheed Martin Aero, Marietta, GA
}

\begin{abstract}
This paper discusses a set of Advisors that help engineers determine when forging is a reasonable fabrication option, and to understand how to design their parts for minimum forging costs. To do this, we took two different approaches: 1) we modified an existing Near Net Shape Process Selection Advisor to include forging as one of the manufacturing processes considered; and 2) we developed a Forging Advisor, which guides the engineer in the specification on the design for forging. In this paper, we will discuss the content of these Advisors and the computer science behind each of the Advisors.
\end{abstract}

\section{Introduction}

As product concepts move through the design cycle, they are shaped by different points of view. Designers must consider functionality, cost, manufacturability, organizational goals, environmental concerns and a host of other factors, all of which involve different points of view, require different technical and social expertise, and afford multiple constraints on product design. This leads to two problems: 1) if a point of view is underrepresented on the project team, it may not be adequately considered. 2) Even when a team considers an area of constraints, they may not have the expertise required to address it properly. We believe knowledge-based Advisors can address both these concerns by providing a formal representation of specialist's knowledge of project teams.

The relationship between design and manufacturing processes is a particularly difficult issue that potentially carries great impact on product cost and performance. Early in conceptual design, engineers focus on developing prototypes that can be made quickly and in small lots to support proof of concept evaluations and tests. They generally select manufacturing processes that support rapid prototyping. As a design moves toward production, engineers must begin considering the demands of larger scale manufacture. Unfortunately, as the design matures, designers may not necessarily question whether alternative processes should be considered for downstream engineering and production, and fail to consider the economies of scale afforded by processes like forging or casting. Also, design decisions made in the early prototype stage may effectively eliminate certain processes as practical solutions.

Forging is one of the processes that often times is not considered early in design, because it is viewed as being too expensive and having too long a lead time to meet prototype and early engineering needs. Unless a component cannot meet performance without being forged, the designers will often select other processes, such as machining for fabricating the prototype 
components. However, there are a number of different ways to look at forging options to make them acceptable both in prototype design, as well as in production.

This paper discusses the design of the Near Net Shape Process Selection System, and its use to perform rapid tradeoffs among fabrication processes any time during the lifecycle of the design, and the Forging Advisor, which provides details on how to design the part for forging to avoid costly mistakes.

A working prototype version of the Near Net Shape Advisor and the Forging Advisor can be accessed at http://www.mpsse.sandia.gov/NNS/nns.applet2.htm. This site shows how the Advisors operate, but is not yet ready for "prime time" as we are still in the process of getting the knowledge.

Both of these Advisors are part of a larger suite of Advisors, which we have been working on for a number of years in the area of manufacturing. These Advisors reside in an Integrated Materials and Process Design Environment (MPDE), which enables the user to pass parameters between Advisors, store session information, and look at a number of different manufacturing processes. The Advisors in this environment include:

- The Materials Selection Advisor

- The Net Shape Process Selection Advisor

- The Forging Advisor

- The Materials and Joining Advisor

- The SmartWeld Advisor

A summary of the architecture used in the development of this environment and details on the Advisors can be found in references [1-5].

For input into the two Advisors, we have relied to date on a design guide for closed-die forgings, which encompasses best practices for specification of designs for forging. Our focus has been on closed-die forgings because these are one of the more predominant forging processes used in aerospace design. As we are still in the early stages of development of these Advisors, we have not yet interviewed forging houses to include their knowledge in the Advisors. However, we will discuss in the "ongoing work" section of this paper how we propose to do this in a way to avoid proprietary issues.

\section{The Near Net Shape Advisor}

\section{Design}

The purpose of the Near Net Shape Process Selection Advisor (NNS Advisor) is to enable the engineer to rapidly analyze trade-offs with respect to geometry, performance and cost among a series of manufacturing processes. The processes we have chosen include 3 types of investment casting, rough machining, forging, and laser enabled net shaping (LENS).

For forging, we chose closed-die forgings, which included blocker forgings, conventional forgings and precision forgings. The parameters we examined included grain flow, performance requirements, function, tolerances, lot size, lead-time, and manufacturability. Because we did not 
have case histories from actual forging houses, we were unable to include microstructure or detailed mechanical property information for specific forged shapes.

\section{Knowledge Representation and Inference Strategies}

Because we intended the Near Net Shape Advisor to be used in very early design, often before the details of product geometry have been fixed, the decision knowledge we wanted to formalize is very heuristic in nature. Although there are factors that may eliminate a given process (e.g., extremely short lead-times or small lot-sizes eliminate precision forging as an option), acceptable processes are usually distinguished from each other by an accumulation of evidence, rather than conclusive, deterministic arguments.

In addition, we wanted an architecture that would make it very easy to add knowledge to accommodate additional processes, product family or contributions from new human experts. This has proven to be an important consideration as we extended the Advisor to the specific needs of the aerospace industry.

To support these constraints we decided on a very simple inference strategy and knowledge representation scheme. Each consultation begins with a set of candidate processes (3 types of casting, 3 types of forging, machining and laser engineered net shaping) and a set of candidate materials. It constructs a set of hypotheses by all possible pairings of process and material. Each hypothesis is a <process, material> pair.

We've encoded process selection knowledge in a set of tests. Each test takes a hypothesis (a <process, material> pair) and a number of parameters (lead-time, complexity, shape, manufacturing constraints, etc.) and returns a number between 0.0 (failure) and 1.0. The inference engine assigns a score to each hypothesis by taking the weighted sum of the results of applying all tests to it:

$$
\operatorname{Score}(H)=\sum w_{i} t_{i}(H)
$$

Where $\mathrm{H}$ is a hypothesis, $\mathrm{t}_{\mathrm{i}}$ is a test and $\mathrm{w}_{\mathrm{i}}$ the weight assigned to it. The weights vary between 0 and 100 , and determine the influence of each test on the final score.

In addition, a test can be optionally categorized as required. If a hypothesis fails any required test, the hypothesis is tagged as failed. This allows us to capture those tests that can eliminate a process from consideration. Although we still present failed hypotheses to the user, the tool highlights them in red to indicate failure.

This representation strategy is not as expressive as approaches such as backward or forward rule chaining. In particular, the only way we can capture interactions between tests is through the very weak summation mechanism. However, by eliminating strong interactions between tests, we have made it very easy to add new knowledge; the tests are completely independent. For domains like ours, where the amount of available knowledge is large and decisions are made by a preponderance of evidence, this seems a valuable trade-off.

\section{Computer Architecture}

We've implemented the Near Net Shape Advisor using a combination of Java applets and servlets. The basic NNS Advisor is implemented as a single applet. It communicates with server-side 
functionality (servlets and Java server pages) to interact with other components of the MPDE architecture (Figure A-1). We chose applets because they allow us to place the Advisor's intelligence on the user's client machine.

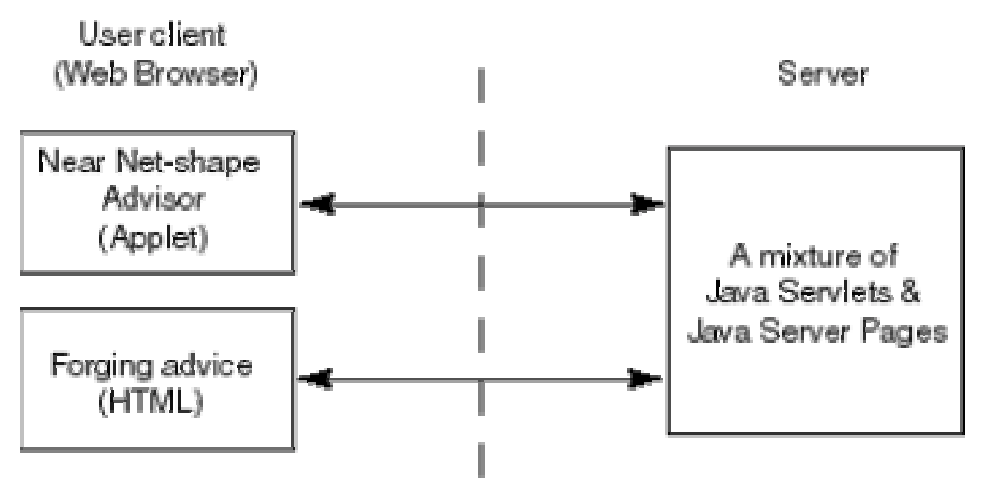

Figure A-1. Communication Diagram Between the NNS and Forging Advisors and the Rest of the Materials and Process Design Environment (MPDE)

The Near Net Shape Advisor applet uses a generic inference engine, written in Java. Figure A-2 shows the basic structure of the Advisor. In this diagram, the Interaction Manager handles all user inputs and display activity. It detects (using the Java event model) when a user has entered a new value, and updates the corresponding parameter. Similarly, it detects when the inference engine has computed a new set of scores and updates the display. All control of user interaction resides in this object. Consequently, the inference engine, tests, parameters and hypotheses are completely independent of any particular interface style or content.

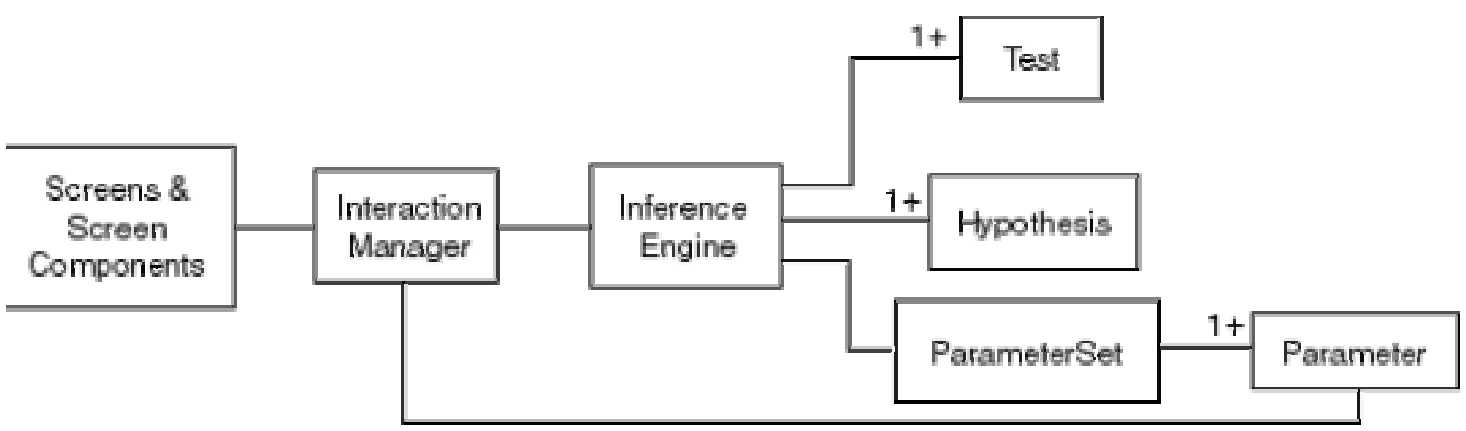

Figure A-2. Basic Structure of the Near Net Shape Advisor

The knowledge in the system resides in three types of objects:

- Hypotheses are the things being evaluated. In the Near Net Shape Advisor, we define a hypotheses to consist of <process, material> pairs.

- User problem data (for example, lead time, lot size, geometric features, etc.) are stored as a set of parameters. There is one parameter for each data item entered. A parameter set groups these parameters into a single object.

- Finally, the inference engine controls a set of tests. Each test in the set is applied to each hypothesis, computing the values in the results table. 
The inference engine runs on a simple, event-driven cycle: when the Interaction Manager detects that the user has entered data on the screen, it sets the value of the associated parameter, and alerts the inference engine to the change. The inference engine then re-evaluates any tests associated with that parameter, and re-computes the scores for all hypotheses. The Interaction Manager then posts the new results to the screen. One important aspect of this approach is that the Advisor does not recompute all tests every time the data changes, but only those tests that involve the changed parameter. This allows the Advisor to perform continuous updates to the screen in a highly efficient manner.

The inference engine is general. We have specialized it to the process selection problem using Java's inheritance mechanism. For example, each test is a specialization of a general test class: it inherits the parent class' general functionality and adds any knowledge specific to that test. The same is true for hypotheses and parameters. In this manner, we may apply the inference engine to suitable, future problem domains.

\section{The Forging Advisor}

\section{Advisor Content}

The Forging Advisor application relies on an Advice Generator to provide a set of detailed recommendations for the forging design. The Advisor offers guidance on forging parameters such as parting line location, draft angles, web thickness, rib height and corner radii. These recommendations are tailored to the specific forging based on specific attributes of the problem, such as the forging process being used, the material being forged, and the desired part geometry. These attributes are passed to the Advice Generator/Forging Advisor from the Net Shape Process Selection Advisor, by selecting the "Get Design Guidelines" button. All of the advice in the Forging Advisor to date has been taken from a forging design guidebook.

Figure A-3 shows one of the first screens that the engineer encounters once they enter the Forging Advisor from the Net Shape Process Selection Advisor. This screen defines the forging process for the engineer and lists the various information links, related to the material and process, which were selected. The screen shown in Figure A-3 is currently under revision, since we are in the midst of adding substantially more links to the page. Figure A-4 shows a typical generic diagram of parting line vs. grain flow examples to help the engineer understand and design their part to obtain the desired grain flow. As we build up case histories from actual forging houses, this simple example will be expanded to include much more complex geometries. Figure A-5 shows the various recommended placements of parting lines as a function of geometry. Included with that are comments to help the engineer avoid common pitfalls. Figure A- 6 shows specific parting line placements as a function of type of forging, in this case a flat-sided forging, and as a function of material. It also provided explanations of why the parting lines are different as a function of material. Under Design Restrictions, a good example of the information provided is shown in Figure A-7. Here for Web Thickness and Rib Height, best practice is outlined for the engineer and a link to tabular information for the actual specifications enables them to ensure that the design meets all the requirements. The last example shows Forging Tolerances as a function of thickness (Figure A-8). Again, there is a link to a specifications table, as well as best practice guides. 
Ele Edt Yien Go Connuricator Help

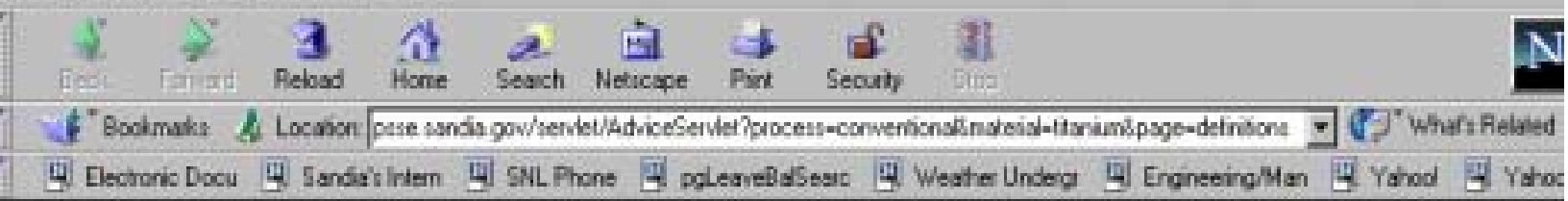

\section{Conventional Forging}

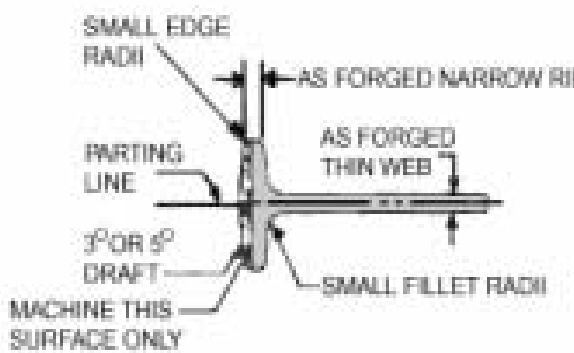

CONVENTIONAL
Conventional die forgngs are more intricate than blocker forgngs with less traft, smaller filet and comer radin, thinner robs and webs, and closer tolerances. Conventional forgings urualy require dies with malaple mpresaions and are more expensive than blocker forgengs. Considerably Jess machining is requered to make a final machined part from a conventional forging than a blockes forging

\begin{tabular}{|c|c|c|}
\hline Forging types & Advantages & Disadvantages \\
\hline $\begin{array}{l}\text { Conventional } \\
\text { closed die } \\
\text { Forging }\end{array}$ & $\begin{array}{l}\text { 1. Machring limited to } \\
\text { face cuts, borng. } \\
\text { sloting, and local } \\
\text { attach areas } \\
\text { 2. More complex } \\
\text { configuration than } \\
\text { blocker } \\
\text { 3. Sharper details } \\
\text { 4. Closer tolerances } \\
\text { 5. More uniform grain } \\
\text { sire and more defined } \\
\text { gain fow than blocker }\end{array}$ & $\begin{array}{l}\text { 1. Higher die cost than } \\
\text { blocker } \\
\text { 2. Additional dies are } \\
\text { required } \\
\text { 3. Stralles forgeable plan } \\
\text { area because of higher } \\
\text { unit pressure } \\
\text { requirement }\end{array}$ \\
\hline
\end{tabular}

\section{Design Considerations}
1. Parting Line Location
2. Size Limitations
3. Desing Restrictions
4. Forging Tolerances

\section{Figure A-3. Home Page for the Forging Advisor}

Design considerations link to specific information about the material, process and part class. 


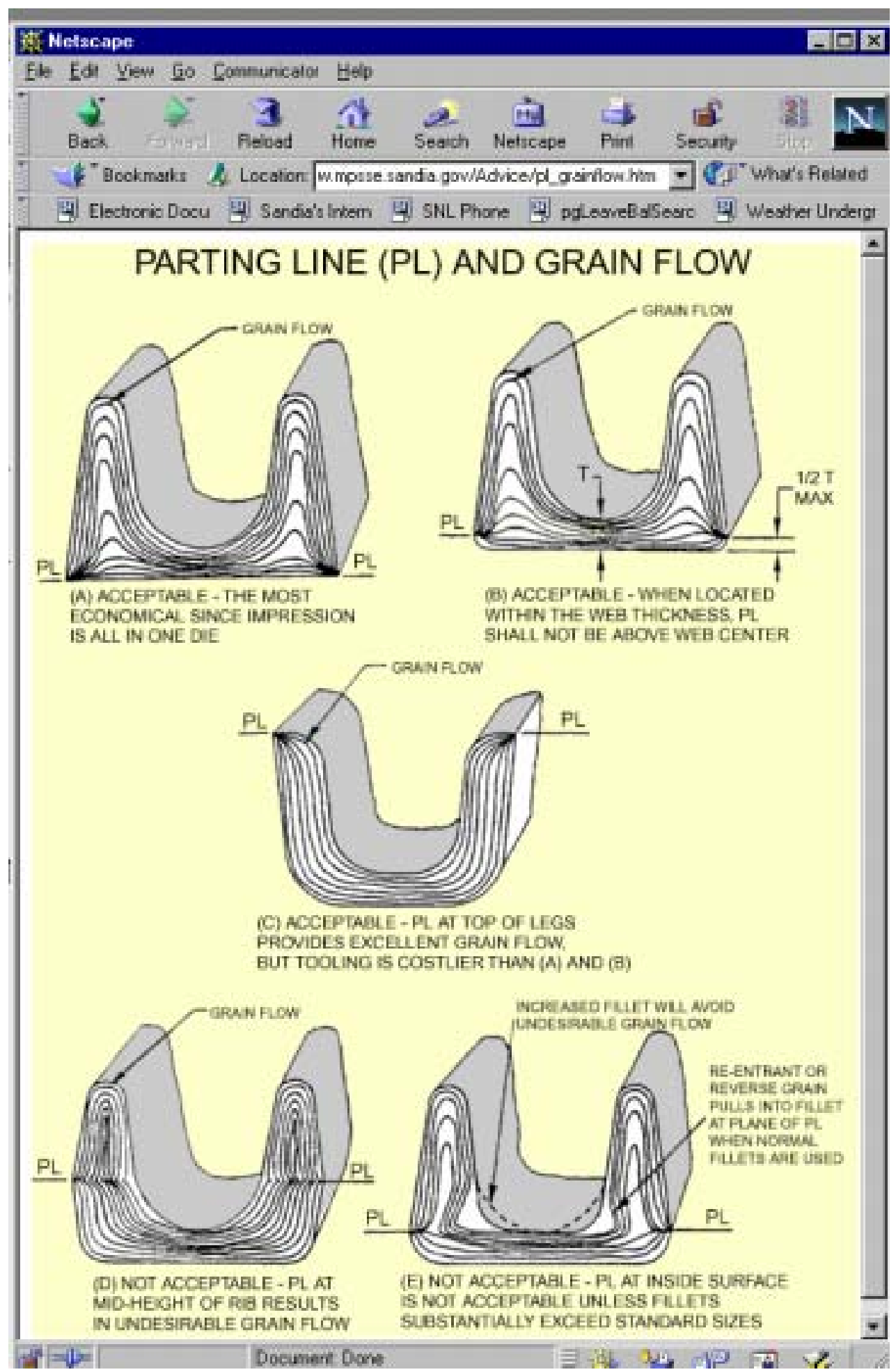

Figure A-4. Grain Flow vs. Parting Line Placement Recommendations 


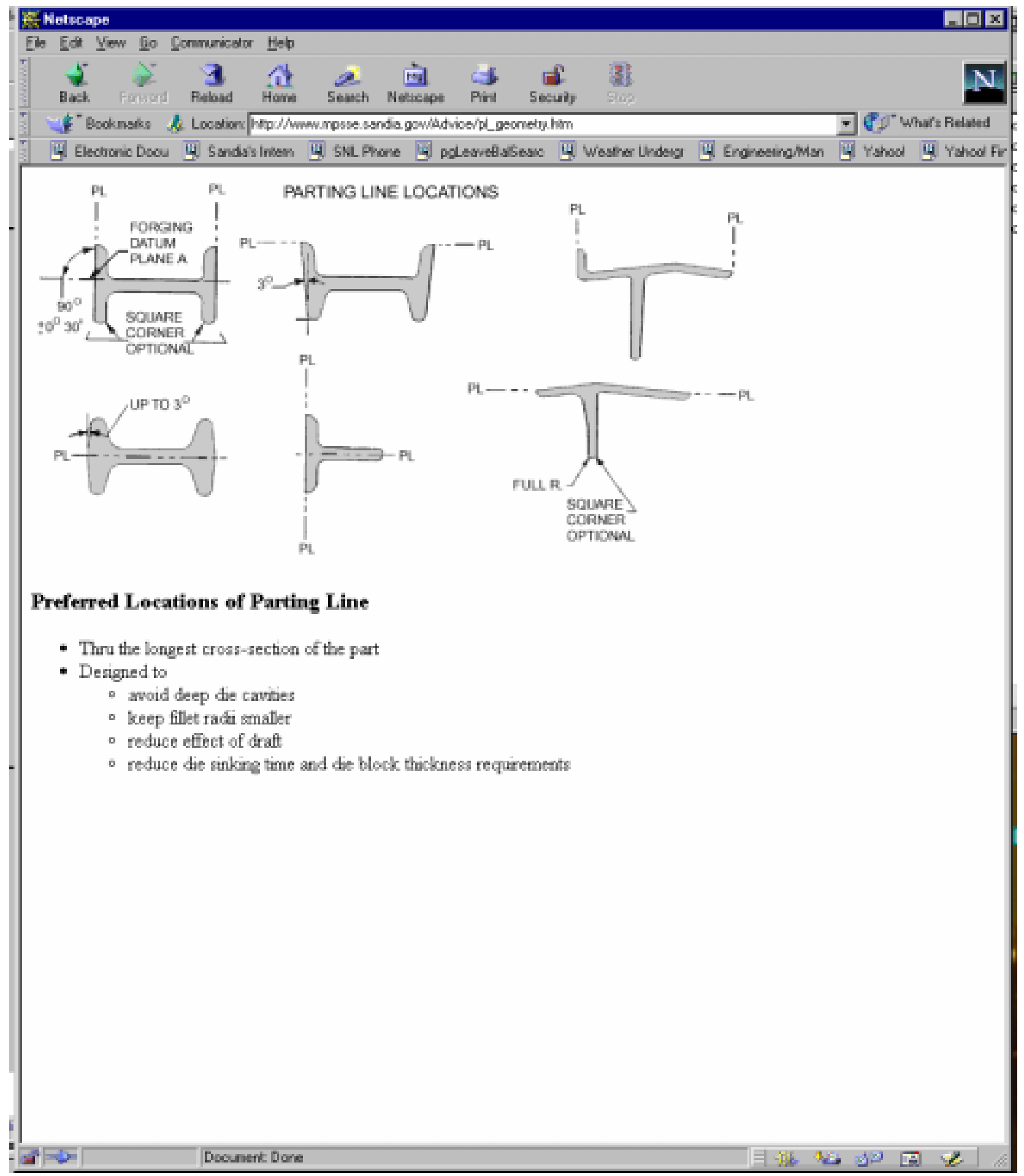

Figure A-5. Parting Line Location as a Function of Part Class 


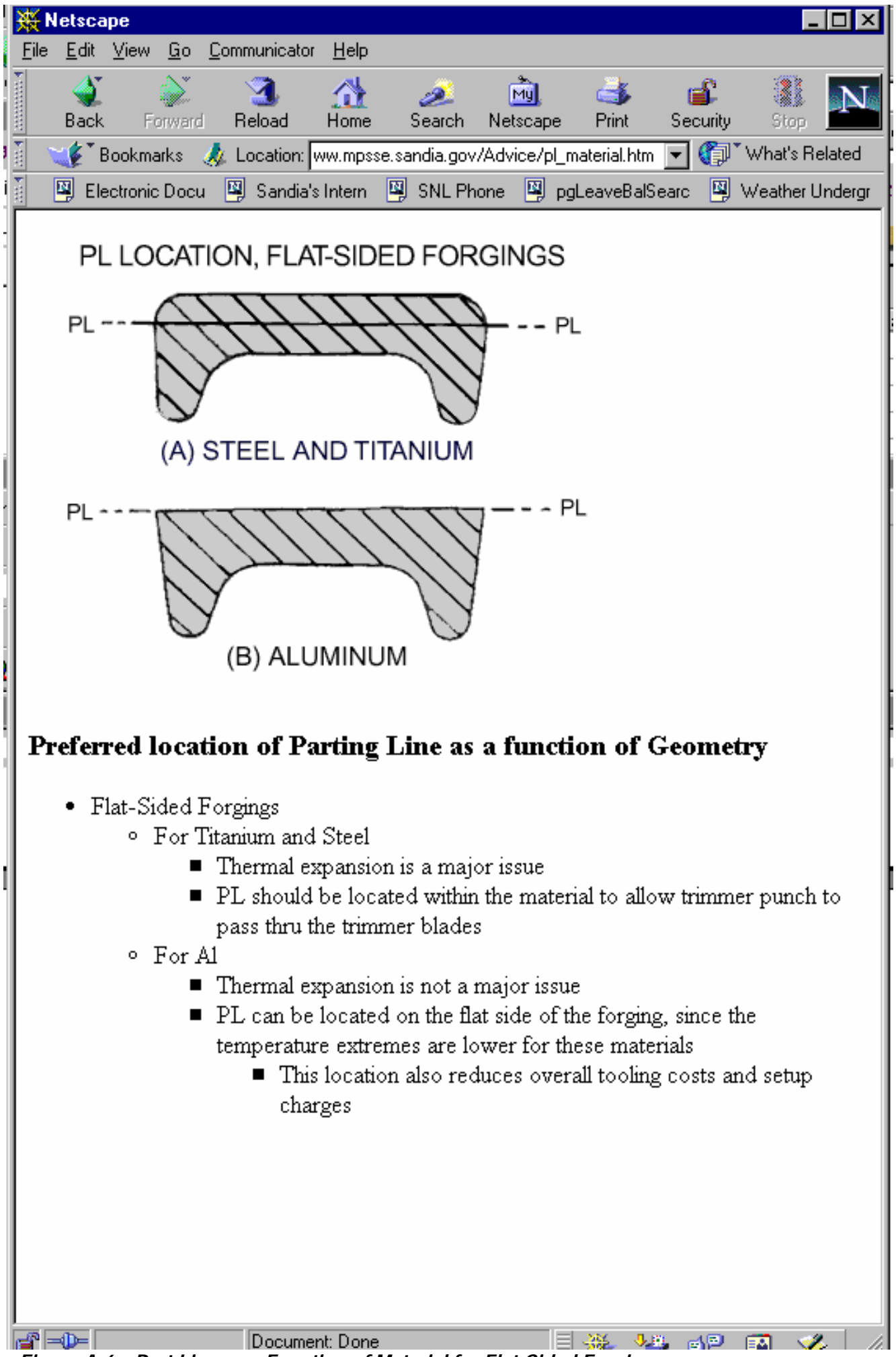

Figure A-6. Part Line as a Function of Material for Flat-Sided Forgings 


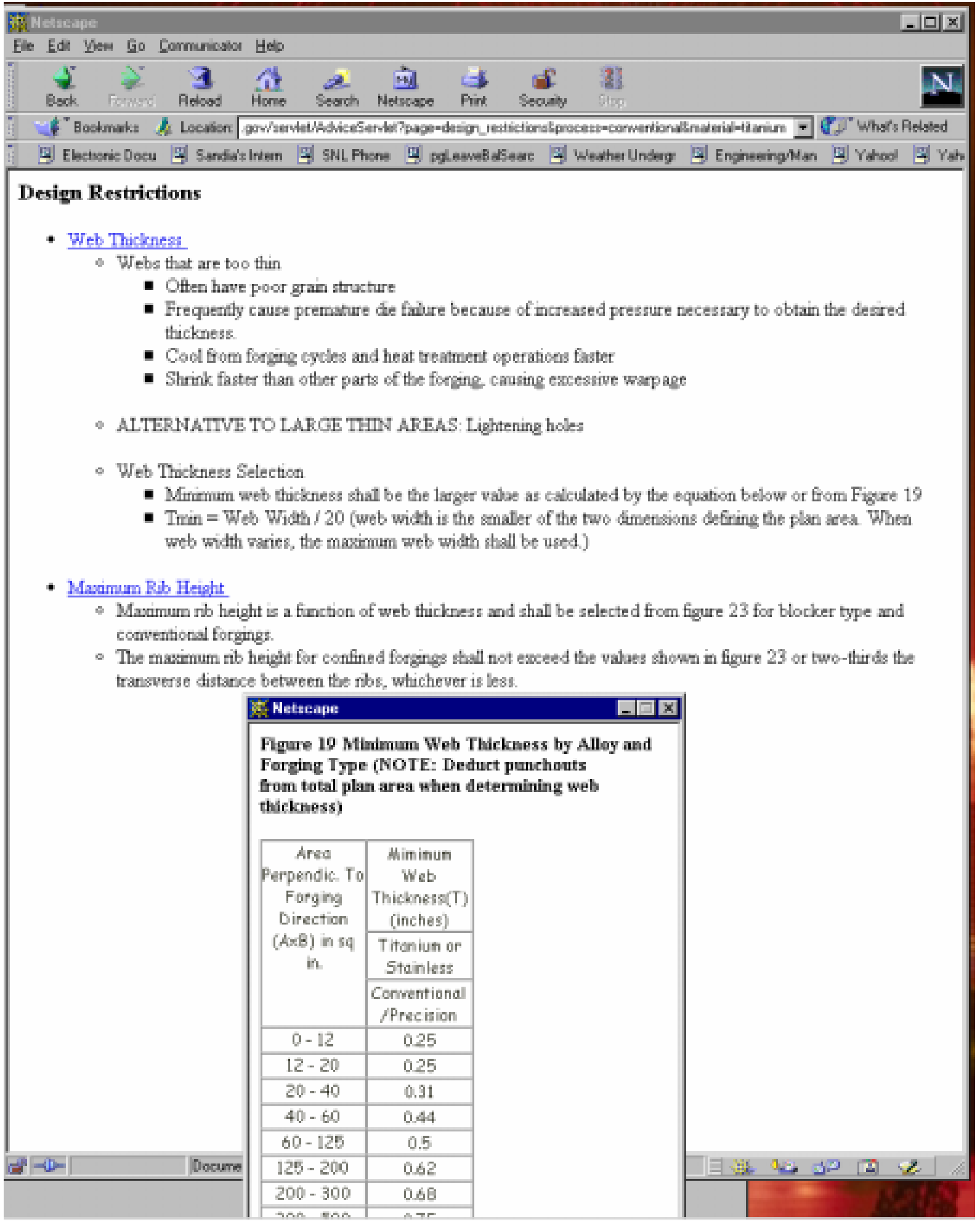

Figure A-7. Design Restrictions of Webs and Ribs

In this case, the information is provided in table form dynamically to the designer. If the part class does not involve webs or ribs, this information would not be accessed. 


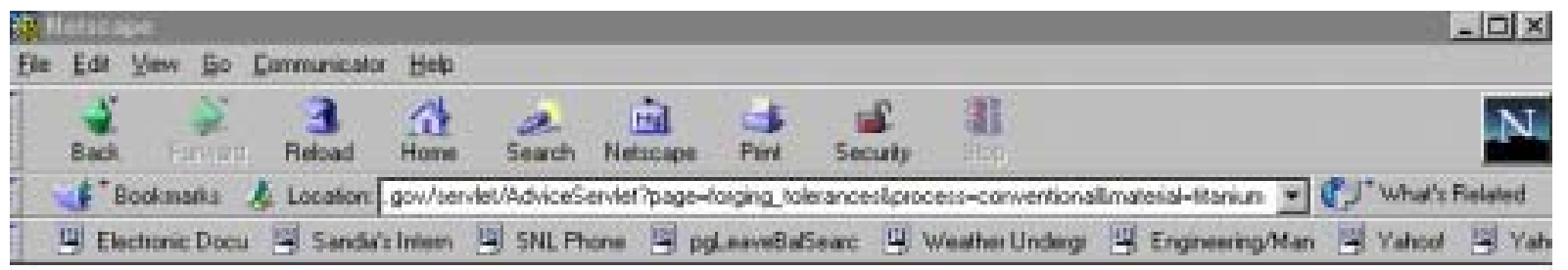

Forging Tolerances

- Thockness Tolerance

- Applies to dmensions between rurfaces formed by opposng des and approxumately parallel to the ram stroke.

- Es a function of forgang type, sire, materal, complezaty, and thickness of webs

- Forging weight is commonly used as a mearure of the required tolerance

- Whenever large production quantites are anticpated or the forging is to be extentuely machined foe fit or function, the stated tolerances shall be ncreased by $50 \%$

- A similar increase as recommended for long thin forgings or where wide sectional variations are encountered, such as maximum rb beight with minimum web thickness.

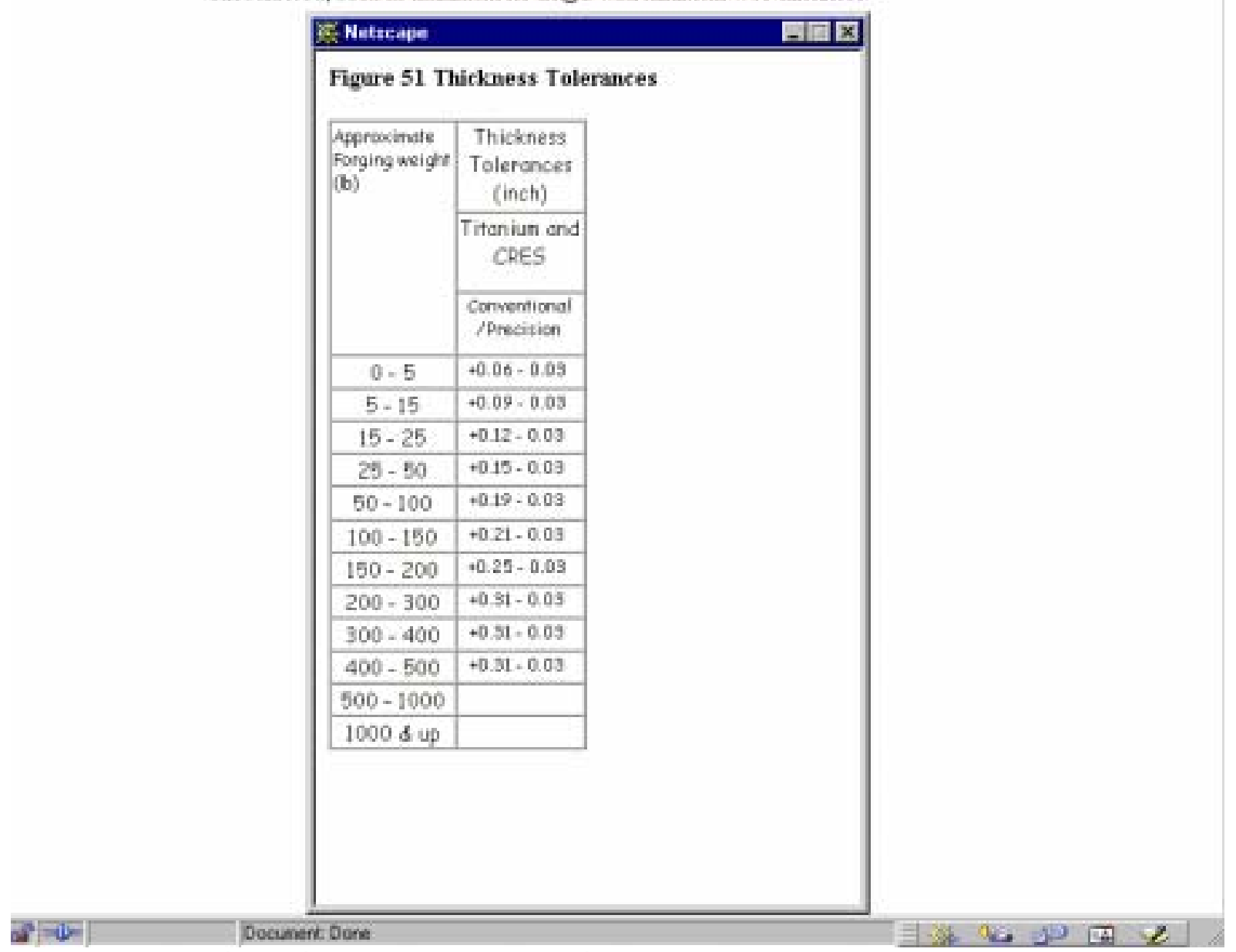

Figure A-8. Example of Tolerance Specifications for the Design

\section{Advice Generator Architecture}

The reasoning logic for the Forging Advisor is based on an Advice Generator. The Advice Generator is a tool for dynamically generating HTML advice documents from a knowledge repository. User input is used to extract and format the subset of rules and knowledge appropriate for the problem being addressed. The Advice Generator accepts a set of parameters describing attributes of the 
problem being solved, and culls the database for knowledge that applies to that particular knowledge domain. The knowledge objects contained in the repository include text, tables, formulas, and images. The Advice Generator makes use of Java Server Page (JSP) technology to define the structure of the advice documents. JSP code is then used to populate the advice template with appropriate knowledge content.

The output of the Advice Generator is a series of linked documents that progress from the most specific level of information to more generalized levels of information. The initial HTML page presented to the user provides a set of specific recommendations based on the problem description. This page provides a single value or an acceptable range of values for the forging parameters when possible. These values may be calculated from formulas or extracted from lookup tables. The more generalized recommendations include hypertext links to reference material that provides a rationale for the recommendations, supporting tables and related information.

\section{Ongoing Work}

Currently, the Forging Advisor builds on information from several design manuals. We are currently arranging to gather knowledge from commercial forging houses on how to design forgings. There are two ways in which we can represent this knowledge:

1. We can represent it as rules (either using the inference engine described above, or a more expressive rule chaining system. The tests will guide the user to determination of parting lines, corner radii, and other design features.

2. Using case-based reasoning. Here, we would not create general rules at all, but would simply store actual cases of forgings that were done by the forging houses, along with descriptions of such properties as grain flow, microstructure, mechanical properties, and relative costs. The challenge here would be to allow the user to easily retrieve those cases that most closely match the product they are designing. We would approach this by selecting attributes (geometry, function, material, etc.) that would be most effective in selecting relevant cases, and indexing them accordingly. Another interesting problem we would have to address in taking this option would be to assist the user in deciding what aspects of a stored case are significant in relation to their current product.

We will decide which of these approaches to take after we have visited the forging houses and analyzed their knowledge and available data.

\section{Acknowledgements}

We would like to acknowledge the support of Dr. Dave Chellman at Lockheed-Martin Aero in Marietta, GA, Dr. Bill Garver at Lockheed-Martin in Ft. Worth, TX and Dr. Michael Collins at Lockheed-Martin Corporate. We would also like to thank Ron Detry, Jim Rice and John Mitchiner at Sandia National Laboratories for encouraging us to perform this work within their organizations. This project was conducted under the Lockheed-Martin Shared Vision Program, Work for Others Funding No. DE-Fl04-00AL66803. 


\section{References}

[1] Mitchiner, K.W., Stubblefield, W.A., Kleban, S.D., and Mitchiner, J.L. (2001). "Implementation of a Materials and Process Design Environment," Sandia National Laboratories SAND report, 1-22.

[2] Kleban, S.D., Stubblefield, W.A., Mitchiner, K.W., Mitchiner, J.L. and Arms, M. (2001). "Collaborative Evaluation of Early Design Decisions and Product Manufacturability," Proceedings of the $34^{\text {th }}$ Annual Hawaii International Conference on System Sciences, 1-10. Wailea, Maui. (proceedings published on a CD)

[3] Kleban, S.D. (1998). "Concurrent Materials and Process Selection in Conceptual Design," Proceedings Artificial Intelligence and Manufacturing Research Planning Workshop, 98-102. Albuquerque, NM: AAAl Press.

[4] Kleban, S.D. (1996). "Design Issues of a Knowledge-based Welding Advisor," Proceedings Artificial Intelligence and Manufacturing Research Planning Workshop, 93-96. Albuquerque, NM: AAAl Press.

[5] Mitchiner, J.L., Kleban, S.D., Hess, B.V., Mahin, K.W., and Messink, D. (1996). "SmartWeld: A Knowledge-based Approach to Welding," Proceedings Artificial Intelligence and Manufacturing Research Planning Workshop, 129-135. Albuquerque, NM: AAAl Press.

[6] SEER Costing Software, Galorath Incorporated, El Segundo, CA. 